\title{
Fasciola hepatica coinfection modifies the morphological and immunological features of Echinococcus granulosus cysts in cattle
}

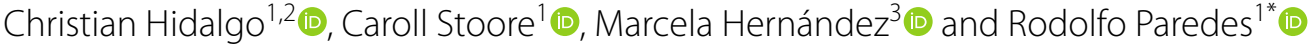

\begin{abstract}
Polyparasitism occurs when animals harbour multiple parasites concomitantly. It is a common occurrence but is generally understudied in wild and domestic animals. Fasciola hepatica and Echinococcus granulosus, which are helminths of ungulates, frequently coinfect cattle. The effects of this particular type of polyparasitism are not well documented. The metacestode of Echinococcus granulosus is surrounded by the adventitial layer, which constitutes the host immune response to the parasite. This layer in cattle is produced by a granulomatous reaction and is involved in echinococcal cyst (EC) fertility. Due to the systemic immune-modulating abilities of Fasciola hepatica, coinfection possibly generates a favourable environment for EC growth. A total of 203 Echinococcus granulosus sensu stricto cysts were found in 82 cattle, of which 42 ECs were found in 31 animals coinfected with Fasciola hepatica. The overall infection intensity was 3 cysts per animal. Coinfection with Fasciola hepatica decreased the mean infection intensity to 1.4 cysts per animal. Regarding EC size, coinfection resulted in smaller ECs (15.91 vs $22.09 \mathrm{~mm}$ ), especially for infertile lung cysts. The adventitial layer of ECs in coinfected animals lacked lymphoid follicles and palisading macrophages, which are generally hallmarks of the granulomatous immune response. The ECs in coinfected animals had organized laminated layers, whereas those in animals without coinfection did not. Although coinfection was not statistically associated with EC fertility, we did not find fertile cysts in the livers of coinfected animals. We concluded that coinfection with Fasciola hepatica and Echinococcus granulosus has a detrimental effect on ECs, particularly infertile cysts.
\end{abstract}

\section{Introduction}

Polyparasitism, which is co-infection with different parasite species in the same host, is a well-documented subject in the medical, veterinary, and zoological literature. Most animals in nature and humans in rural areas are concurrent hosts of a wide array of parasites [1]. Although polyparasitism sometimes affects the viability of the parasite within its host or its transmission to other hosts, it is a poorly studied aspect of parasitism, particularly in terms of the synergistic or antagonistic relationship that occurs between two parasites within

\footnotetext{
*Correspondence: rparedes@unab.c

${ }^{1}$ Laboratorio de Medicina Veterinaria, Escuela de Medicina Veterinaria, Facultad de Ciencias de la Vida, Universidad Andres Bello, Santiago, Chile Full list of author information is available at the end of the article
}

the same host [2]. These interactions occur when the presence of one parasite creates an environment that facilitates or impedes, direct or indirectly, infection with another parasite [1]. In this way, polyparasitism increases or decreases the susceptibility of the host to other infections, which are sometimes fatal [3-6]. Despite being extremely relevant for the comprehension of the hostparasite relationship, the information found in the literature that illustrates the real effects of polyparasitism on host health is scarce [1]. As many parasitic diseases are also zoonoses, it is an important issue in both animal and human health.

The diverse group of helminth parasites known as "masters of immune modulation" is a group of animals that show various infection strategies that generally induce a "Th2-like" immune response [7-10]. This type

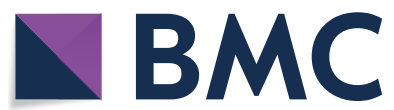

(c) The Author(s) 2020. This article is licensed under a Creative Commons Attribution 4.0 International License, which permits use, sharing, adaptation, distribution and reproduction in any medium or format, as long as you give appropriate credit to the original author(s) and the source, provide a link to the Creative Commons licence, and indicate if changes were made. The images or other third party material in this article are included in the article's Creative Commons licence, unless indicated otherwise in a credit line to the material. If material is not included in the article's Creative Commons licence and your intended use is not permitted by statutory regulation or exceeds the permitted use, you will need to obtain permission directly from the copyright holder. To view a copy of this licence, visit http://creativeco mmons.org/licenses/by/4.0/. The Creative Commons Public Domain Dedication waiver (http://creativecommons.org/publicdomain/ zero/1.0/) applies to the data made available in this article, unless otherwise stated in a credit line to the data. 
of immune response against parasites normally controls the infection but rarely eliminates the parasite. This shows that helminths have developed mechanisms of both evasion and modulation of the immune response by taking advantage of host tolerance and anti-inflammatory mechanisms [8].

Experimental studies of co-infection with parasites with similar characteristics show that they often compete for their ecological niche [11]. Experiments in rats with Moniliformis moniliformis and Hymenolepis diminuta determined that in single infections, both parasites are localized in the anterior portion of the small intestine, whereas in coinfections, Hymenolepis diminuta is pushed to a posterior segment; interestingly, Hymenolepis diminuta lives longer than Moniliformis moniliformis, and once the latter dies, Hymenolepis diminuta moves to its preferred anatomical place [1]. Another example is nematodes from the Steinernema and Heterorhabditis genera [11].

In cattle, there are two zoonotic parasitic helminths that are frequently found coinfecting the same host: Echinococcus granulosus and Fasciola hepatica, which are a cestode and a trematode, respectively. Echinococcus granulosus has an indirect life cycle [12] in which cattle and other ungulates are intermediate hosts and dogs are definitive hosts. In the intermediate host, the metacestode of Echinococcus granulosus develops as cysts in the liver, lungs, and other viscera, causing a disease termed cystic echinococcosis [13]. Echinococcus cysts (ECs) are maintained by a syncytium of cells called the germinal layer, which synthesizes an extracellular matrix termed the laminated layer that forms protoscoleces through cellular differentiation processes. Both layers are encapsulated by a third layer of host origin named the adventitial layer [14]. Fasciola hepatica also has an indirect life cycle, with cattle as the definitive host. The adult fluke lives in the bile ducts [15].

Two types of Echinococcus cysts are found in the intermediate hosts. Fertile ECs, characterized by the presence of protoscoleces, are infective in the definitive host, which enables them to continue their life cycle. Infertile ECs either do not have or have only a few nonviable protoscoleces. The cellular and molecular mechanisms that cause EC infertility remain unknown [16]. We previously reported that cattle age is not associated with EC fertility [17]. Studies point towards the local immune response as the most likely cause [18-23]. In cattle, the EC adventitial layer is characterized by a granulomatous reaction with an accumulation of monocytic cells, which are believed to be in control of isolating and destroying a persistent foreign body. The hallmarks of this reaction are two special kinds of macrophages called epithelioid cells and giant multinucleated cells [24]. Studies on cattle that describe their cellular components refer to the adventitial layer as the host-derived fibrous capsule [25-32]. One study of fertile liver cysts found a significant number of $B$ cells and some polymorphonuclear cells and monocytes [25]. Another study compared ECs between sheep and macropods, reporting that fertile cysts have either foamy macrophages and giant multinucleated cells or fibrous granulation tissue devoid of cells [27]. The authors pondered whether fertile cysts develop under inflammatory conditions. In the case of infertile cysts, Sakamoto and Cabrera [29] described the cellular components of the adventitial layer of infertile cysts with lymphocytes, macrophages, granulocytes, and giant multinucleated cells. They also reported that cyst size is correlated with the type of cells present in the adventitial layer: small infertile cysts are surrounded by macrophages, while larger cysts are surrounded by eosinophils.

Although Echinococcus granulosus and Fasciola hepatica belong to different taxonomical categories, they have common antigens. Sera from animals experimentally infected with Fasciola hepatica or Echinococcus granulosus recognize antigens from Schistosoma mansoni. When rabbits are immunized with Echinococcus granulosus antigens, their sera recognize the 205, 166, 45 and $32 \mathrm{kDa}$ proteins of Fasciola gigantica, as shown by a Western blot assay. Likewise, when animals are immunized with Fasciola gigantica antigens, their sera recognize Echinococcus granulosus the 205, 148 and $32 \mathrm{kDa}$ protoscolex antigens [33].

Th2-like immune modulation induced by both Fasciola hepatica and Echinococcus granulosus, along with their similar immune modulation strategies, should favour the development of both parasites. However, cattle with both Fasciola hepatica and Echinococcus granulosus have an decreased proportion of liver cysts and an increased proportion of small lung cysts [17]. It is possible that this non-specific occurrence is due to liver damage caused by Fasciola hepatica. However, the increased proportion of small lung cysts suggests a systemic effect exerted by Fasciola hepatica infection. These systemic effects in coinfections with other pathogens are well studied. Fasciola hepatica inhibits the $\mathrm{T}_{\mathrm{H}} 1$ response against Bordetella pertussis [34] and inhibits the cellular immune response against Mycobacterium tuberculosis [35]. This research article suggests that Fasciola hepatica coinfection has a systemic effect on the Echinococcus granulosus metacestode, which affects both the number and size of ECs present in coinfected animals. Our study provides a deeper characterization of the adventitial layer of the EC and the way in which Fasciola hepatica coinfection affects the local immune response against Echinococcus granulosus. 


\section{Materials and methods Sample collection}

Samples were collected from abattoirs at three different geographical locations in the Metropolitan $\left(33.4489^{\circ} \mathrm{S}, 70.6693^{\circ} \mathrm{W}\right)$, Los Lagos $\left(40.5762^{\circ} \mathrm{S}\right.$, $\left.73.1149^{\circ} \mathrm{W}\right)$ and Magallanes $\left(53.1638^{\circ} \mathrm{S}, 70.9171^{\circ}\right.$ W) regions over a seven-day period at each location. According to local animal health authorities, more than $90 \%$ of viscera confiscation in cattle is caused by either Fasciola hepatica and/or Echinococcus granulosus [36]. During the slaughtering process, all livers were inspected for Fasciola hepatica and Echinococcus granulosus infections, while lungs were inspected only for Echinococcus granulosus infection. Fasciola hepatica infections were determined as previously described [17]. Only adult animals ( $>2$ years) were sampled. Each EC was obtained from the viscera, placed into a labelled sealed bag and stored in an isothermal container. Each bag represented all the ECs obtained from each slaughtered animal with or without coinfection. All sampling procedures were approved by the Universidad Andres Bello Bioethics Committee (protocol number 016/2016).

\section{Sample processing}

In the laboratory, each cyst was individually identified with a corresponding number identifying the organ (liver or lung) and the host (single or multiple cysts) and measured with a digital caliper. Using a sterile syringe, the hydatid fluid was removed and stored. Using a disposable scalpel, the cyst was opened along the longest longitudinal axis, and fertility was assessed as previously described [37]. EC fertility was determined by the presence of a white laminated layer that easily detaches from the adventitial layer and protoscoleces floating in the remaining hydatid fluid and/or attached to the inside of the cyst. ECs with a yellow-ochre laminated layer firmly attached to the adventitial layer with clear hydatid fluid were considered infertile. Suspicious ECs were examined under a light microscope for fertility assessment (i.e., those with a whitish laminated layer without protoscoleces floating in the remaining fluid or attached to the inside of the cyst). Gross EC features were also recorded. Five different germinal/laminated layer colours were recognized: white, yellow, calcified, haemorrhagic, and mixed white/yellow. ECs presented as either one chamber or multiple chambers. Regardless of colour, some ECs presented patches of haemorrhage. These classifications are depicted in Figure 1.

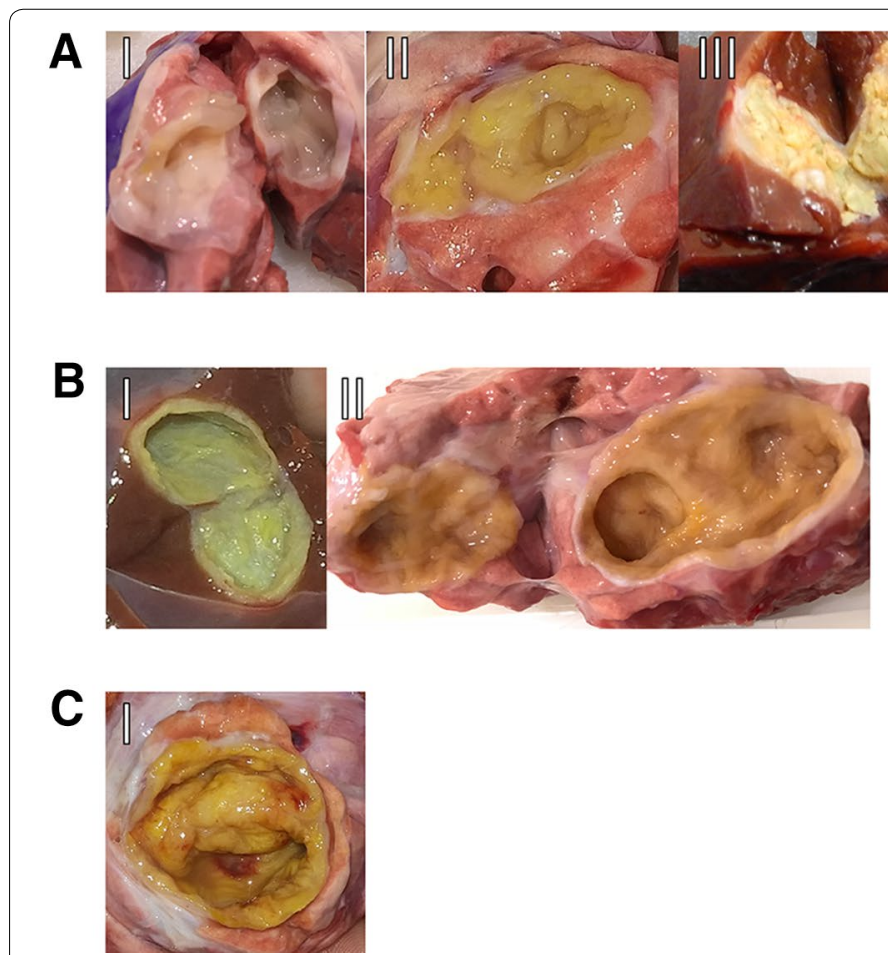

Figure 1 Gross echinococcal cyst features. A Representative images of white (I), yellow (II), calcified (III), haemorrhagic (IV) and mixed white/ yellow (V) germinal/laminated layer colours. B Representative images of ECs with one chamber (I) or multiple chambers (II). C Representative image of a yellow-coloured EC with a haemorrhagic patch. EC: Echinococcus cyst. 


\section{DNA processing and analysis}

To determine the Echinococcus granulosus species, the full length of the mitochondrial cox1 gene was amplified and sequenced as previously described [38, 39]. Briefly, DNA was extracted using a commercial kit (Promega ReliaPrep gDNA Tissue Miniprep). Fifty nanograms of DNA was used for PCR, and products were visualized in $1 \%$ agarose gels with SYBRsafe stain. Sample sequencing was performed with $50 \mu \mathrm{L}$ of PCR product and two primers. Finally, both the forward and reverse sequencing data were imported into Geneious software and aligned using the Eg01 haplotype sequence as a template (Accession No. JQ250806). Only samples that represented Echinococcus granulosus sensu stricto were included in this study.

\section{Histological processing and analysis}

Samples were processed as previously described [40]. Briefly, fixed samples were cut, oriented transversally and inserted into biopsy cassettes. Paraffin embedding was performed in a Leica Tissue Processing station using a 12-h protocol. Paraffin blocks were made using a Leica inclusion station. Afterwards, each block was cut into $5-\mu \mathrm{m}$ tissue sections using a Leica microtome. Each slide was stained with haematoxylin and eosin (HE). For each cyst sample, two slides were examined under an inverted light microscope (Olympus FSX100), and both the laminated and adventitial layers were analysed.

An image of each slide was obtained at low-power magnification that contained a total length of 4 to $5 \mathrm{~mm}$ of the laminated layer. Ten measurements of thickness were made across the whole length of the sample.

\section{Adventitial layer morphohistological analysis}

The criteria used to determine if a histological feature was present in each slide are found in Table 1. A representative image of each feature is shown in Figure 2.

\section{Statistical analysis}

All data were recorded and analysed in both GraphPad Prism version 8.00 for Mac OSX, (GraphPad Software, La Jolla, USA) and Stata v12. Data distribution was assessed by the Shapiro-Wilk test. Quantitative nonnormally distributed data and ordinal variables are presented as the median and IQR, and nonparametric Mann-Whitney tests were performed. The Chi square test was used for determining the statistical associations between nominal variables. $P$ values below the 0.05 threshold were considered statistically significant.

\section{Results}

Global cattle coinfection status

A total of 204 ECs were found in 83 cattle. After molecular identification, only one EC was determined to be $E$. ortleppi and was removed from the study, bringing the total number of samples to 203. Of these, 42 ECs (20.6\%) were found in 31 animals coinfected with Fasciola hepatica (15 liver cysts and 27 lung cysts). The overall infection intensity was 3 cysts per animal. Cattle coinfected with Fasciola hepatica had a mean infection intensity of 1.4 cysts per animal. Non-co-infected animals had a significantly higher mean infection intensity of 4.2 cysts per animal $(p=0.0006)$ (Figure 3).

\section{Co-infection and EC fertility}

No fertile liver ECs were found in animals coinfected with Fasciola hepatica. There was no statistical association

Table 1 Criteria for determining the presence of the histological characteristics of the adventitial layer.

\begin{tabular}{|c|c|c|}
\hline & Histological feature & Criteria \\
\hline Laminated layer disorganization & $\begin{array}{l}\text { Either whole laminated segments inside the adventitial } \\
\text { layer or host cell infiltration between the laminated } \\
\text { layer sheets }\end{array}$ & At least one in the entire sample \\
\hline $\begin{array}{l}\text { Necrosis between the laminated } \\
\text { and adventitial layer }\end{array}$ & $\begin{array}{l}\text { Presence of an eosinophilic zone devoid of cells without } \\
\text { a fibrous structure }\end{array}$ & $\begin{array}{l}\text { Across one low-power magnification field (approximately } \\
5 \mathrm{~mm} \text { ) }\end{array}$ \\
\hline Calcifications & $\begin{array}{l}\text { Presence of strong haematoxylin staining without cells } \\
\text { and with crystal structures }\end{array}$ & At least one in the entire sample \\
\hline Host cells in the germinal layer & As previously described [42] & At least one in the entire sample \\
\hline Giant multinucleated cells & Cells with 5 or more nuclei near the laminated layer & At least one per high-power magnification field (1 mm) \\
\hline Palisading macrophages & $\begin{array}{l}\text { The presence of foamy macrophages with cytoplasmic } \\
\text { projections in contact with the laminated layer }\end{array}$ & Across one low-power magnification field \\
\hline Lymphoid follicles & $\begin{array}{l}\text { Circular structures with lymphocytes near the laminated } \\
\text { layer }\end{array}$ & At least one per low-power magnification field \\
\hline Eosinophils & $\begin{array}{l}\text { Cells with eosinophilic cytoplasm near the laminated } \\
\text { layer }\end{array}$ & $\begin{array}{l}\text { At least ten or more eosinophil nuclei per high-power } \\
\text { magnification field }\end{array}$ \\
\hline
\end{tabular}

When a feature was not recorded in both slides, it was considered absent. 




Figure 2 Adventitial layer histological features. Histological sections of the adventitial layer of cattle ECs with different features. A Laminated layer disorganization. B Necrosis between the laminated and adventitial layers. C Calcifications. D Host cells in the germinal layer. E Giant multinucleated cells. F Palisading macrophages. G Lymphoid follicles. H Eosinophils. Arrows mark indicated feature. Stain: haematoxylin and eosin. EC: Echinococcus cyst.

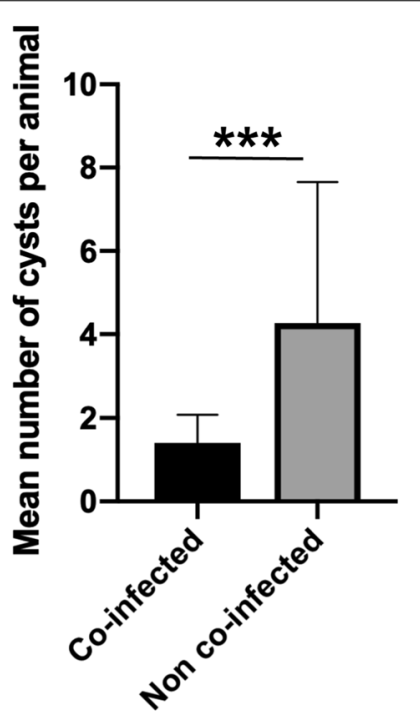

Figure 3 Intensity of Echinococcus granulosus infection in cattle coinfected with Fasciola hepatica. The results are expressed as the mean number of ECs per animal \pm standard deviation. Statistical significance at $p<0.05,{ }^{* *} p<0.01{ }^{* * *} p<0.001$. EC: Echinococcus cyst. between the presence of Fasciola hepatica and EC fertility in the lungs (Fisher's exact test, $p=0.35$ ) or liver (Fisher's exact test, $p>0.99$ ). The numbers of fertile and infertile cysts are summarized in Table 2 .

\section{Coinfection and EC size}

The mean diameter of ECs in animals with Fasciola hepatica coinfection $(15.91 \mathrm{~mm})$ was significantly smaller $(p=0.0243)$ than that of ECs in animals without coinfection $(22.09 \mathrm{~mm})$ (Figure 4A). When analysed according to organ location, the ECs in lungs in co-infected animals were smaller $(19.38 \mathrm{~mm})$ than ECs in non-co-infected animals $(28.29 \mathrm{~mm})(p=0.0212)$ (Figure 4B). When analysed according to fertility, infertile ECs were smaller $(17.92 \mathrm{~mm})$ in coinfected animals than those in non-coinfected $(26.07 \mathrm{~mm})$ animals $(p=0.0066)$ (Figure $4 \mathrm{C})$.

\section{Coinfection and gross hydatid cyst features}

There were no statistical associations between Fasciola hepatica coinfection and the presence of haemorrhagic patches or the presence of single or multiple chambers in

Table 2 Fertility of ECs from both the liver and lungs of cattle coinfected with Fasciola hepatica.

\begin{tabular}{|c|c|c|c|c|c|c|}
\hline & \multicolumn{2}{|l|}{ Liver } & \multicolumn{2}{|l|}{ Lungs } & \multicolumn{2}{|l|}{ Total } \\
\hline & Fertile & Infertile & Fertile & Infertile & Fertile & Infertile \\
\hline Co-infected & 0 & 15 & 3 & 24 & 3 & 39 \\
\hline Non-co-infected & 1 & 70 & 4 & 86 & 5 & 156 \\
\hline
\end{tabular}

EC: Echinococcus cyst. 

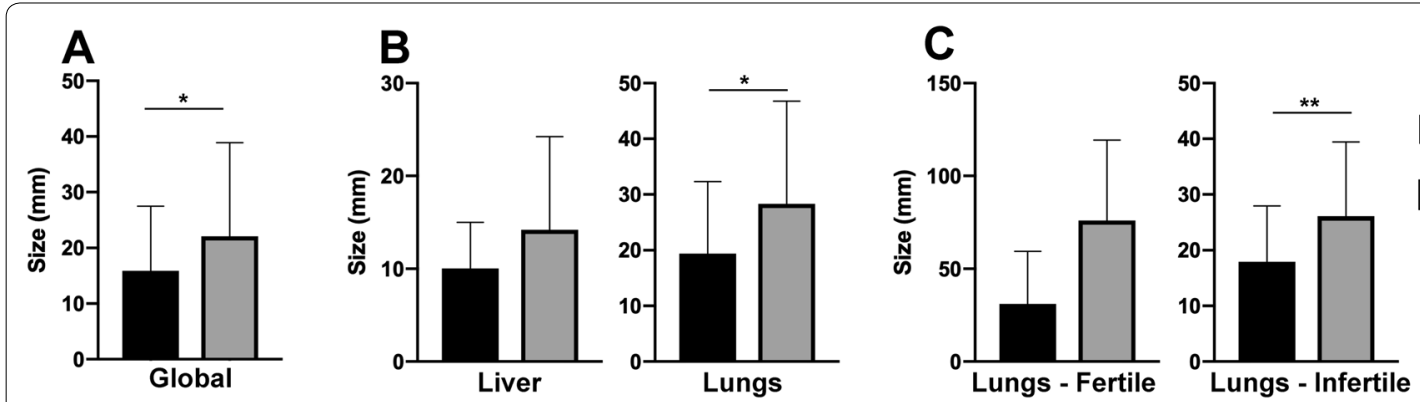

Co-infected

Non co-infected

Figure 4 EC mean diameter in cattle with or without Fasciola hepatica coinfection. A Global difference in size; coinfected animals had smaller ECs. B Difference between liver and lung ECs; coinfection was associated with smaller lung cysts. C Difference between fertile and infertile lung ECs; infertile cysts were smaller in coinfected animals. The results are expressed as the mean size of ECs \pm standard deviation. Statistical significance at $p<0.05,{ }^{* *} p<0.01{ }^{* * *} p<0.001$. EC: Echinococcus cyst.

ECs. Regarding the inner chamber colour, Fasciola hepatica coinfection was associated with an overall decreased proportion of cysts with the mixed yellow/white phenotype $(p=0.0082)$, and only one case of a cyst with a haemorrhagic inner chamber was recorded. These results are summarized in Table 3.

\section{Co-infection and adventitial layer features}

The adventitial layer of 185 ECs was analyzed (twelve liver and 23 lung cysts from coinfected animals and 62 liver and 88 lung cysts from non-coinfected animals). In each sample, Fasciola hepatica coinfection was associated with the presence or absence of the following inflammatory features: laminated layer disorganization, necrosis between the laminated layer and adventitial layer, calcifications, host cells infiltrating the germinal layer, giant multinucleated cells, palisading macrophages, lymphoid follicles, and eosinophils.

Coinfection was associated with an absence of laminated layer disorganization $(p=0.0043)$, palisading macrophages $(p=0.0009)$, and lymphoid follicles in the adventitial layer $(p=0.0003)$. The results are summarized in Table 4. Regarding Fasciola hepatica coinfection and the laminated layer thickness, there was no association of fertile or infertile cysts with thinner or thicker laminated layers.

In summary, Fasciola hepatica coinfection had a paradoxical effect on ECs, as it was associated with the absence of fertile ECs in the liver, decreased infection intensity, and decreased EC size. However, it was also associated with an absence of inflammatory features in the adventitial layer, such as laminated layer disorganization, palisading macrophages, and lymphoid follicles.

\section{Discussion}

Polyparasitism of Fasciola hepatica and Echinococcus granulosus is a common occurrence that is not often reported in scientific studies. A previous study found that $46.57 \%$ of E. granulosus-infected cattle harbour both parasites simultaneously [17], which was a higher percentage than that found this report. We found that $F$. hepatica infection also decreases the E. granulosus infection intensity. This leads to the overrepresentation of the percentage of ECs in non-co-infected animals, as these animals harbour a higher number of ECs than co-infected animals. Additionally, fertile liver ECs were only found in the absence of Fasciola hepatica infection. While this observation suggests a detrimental effect of Fasciola hepatica on the E. granulosus metacestode, coinfected and noncoinfected cattle did not show significant differences in the fertility of ECs in the liver and lungs. The cause of this effect is not known. Due to liver damage caused by both acute and chronic Fasciola hepatica infection [41], it is plausible that Echinococcus granulosus oncospheres are unable to thrive in the liver, and only those that travel via lymph towards the lungs are able to fully

Table 3 Distribution of the inner chamber colours of Echinococcus cysts according to Fasciola hepatica coinfection.

\begin{tabular}{lcccccc}
\hline & \multicolumn{2}{l}{ Inner chamber colour } & & & Haemorrhagic & Mixed \\
\cline { 2 - 6 } & White & Yellow & Calcified & Total \\
\hline Co-Infected & 6 & 18 & 4 & 1 & 5 & 34 \\
Non-Co-Infected & 6 & 101 & 12 & 0 & 28 & 147 \\
Total & 12 & 119 & 16 & 1 & 33 \\
\hline
\end{tabular}


Table 4 Presence or absence of adventitial layer features of ECs with and without Fasciola hepatica coinfection.

\begin{tabular}{|c|c|c|c|c|}
\hline & \multicolumn{2}{|c|}{ Laminated layer disorganization } & \multicolumn{2}{|c|}{$\begin{array}{l}\text { Necrosis between the laminated } \\
\text { and adventitial layer }\end{array}$} \\
\hline & Absence & Presence & Absence & Presence \\
\hline Co-infected & $24^{* *}$ & $11^{* *}$ & 13 & 22 \\
\hline \multirow[t]{3}{*}{ Non-co-infected } & $61^{* *}$ & $89^{* *}$ & 39 & 111 \\
\hline & \multicolumn{2}{|c|}{ Calcifications } & \multicolumn{2}{|c|}{ Host cells in the germinal layer } \\
\hline & Absence & Presence & Absence & Presence \\
\hline Co-infected & 30 & 5 & 26 & 9 \\
\hline \multirow[t]{3}{*}{ Non-co-infected } & 108 & 42 & 102 & 48 \\
\hline & \multicolumn{2}{|c|}{ Giant multinucleated cells } & \multicolumn{2}{|c|}{ Palisading macrophages } \\
\hline & Absence & Presence & Absence & Presence \\
\hline Co-infected & 2 & 33 & $7^{* * *}$ & $28^{* * *}$ \\
\hline \multirow[t]{3}{*}{ Non-co-infected } & 13 & 137 & $4^{* * *}$ & $146^{* * *}$ \\
\hline & \multicolumn{2}{|c|}{ Lymphoid follicles } & \multicolumn{2}{|c|}{ Eosinophils } \\
\hline & Absence & Presence & Absence & Presence \\
\hline Co-infected & $10^{* * *}$ & $25^{* * *}$ & 2 & 33 \\
\hline Non-co-infected & $8^{* * *}$ & $142^{* * *}$ & 1 & 149 \\
\hline
\end{tabular}

EC: Echinococcus cyst.

Statistical significance at $p<0.05,{ }^{* *} p<0.01{ }^{* * *} p<0.001$, Fisher's exact test.

develop [17]. This may explain the decreased intensity of infection observed in naturally coinfected cattle. Another variable that affects the intensity of infection is weather. It also directly affects oncosphere viability. Higher temperatures and direct sunlight confer oncospheres the ability to infect intermediate hosts [42]. One of the regions that was sampled may confound our results, as it has both optimal climatic conditions for oncosphere survival and is free of Fasciola hepatica. Exclusion of the samples from this region from the analysis did not affect our results. Notably, regardless of coinfection status, the overall intensity of infection in this study (3 cysts per animal) is lower than that reported for cattle elsewhere [43, 44].

Cattle EC size varies across studies and the type of viscera. One study showed that lung cysts are larger than liver cysts (mean diameters of $43.1 \mathrm{~mm}$ and $35.2 \mathrm{~mm}$, respectively) [44]. A second study showed cyst sizes ranging from 4 to $108 \mathrm{~mm}$, with most cysts measuring between 11 and $50 \mathrm{~mm}$ [45]. Both studies reported a higher intensity of infection in the lungs than in the liver but did not mention coinfections with other parasitic diseases. Our results show that lung ECs are larger than liver cysts. Fasciola hepatica coinfection is associated with smaller cyst sizes, specifically for infertile lung cysts. On average, infertile lung cysts were half the size in coinfected animals compared to those in non-coinfected animals. To the best of our knowledge, this is the first study that associates cattle hydatid cyst size with Fasciola hepatica coinfection.

EC fertility is associated with the intensity of the inflammatory reaction in the adventitial layer [40], and Fasciola hepatica modifies the cattle systemic immune response [35]. We hypothesized that adventitial layer characteristics are associated with coinfection status. This study shows that coinfection is associated with an absence of both lymphoid follicles and laminated layer disorganization in the adventitial layer of liver ECs. Lung ECs frequently show an absence of calcification, necrosis under the laminated layer, and palisading macrophages of the adventitial layer. These findings suggest a positive environment for EC growth, as the presence of these histological features is the hallmark of the granulomatous reaction associated with EC infertility [40]. Fasciola hepatica modulates host macrophages, stimulates fibrosis, and inhibits TLR3 and TLR4 activity (both of which are $\mathrm{T}_{\mathrm{H}} 1$-associated receptors and thus are detrimental for EC survival) [46]. This is a possible mechanism by which the granulomatous reaction is diminished. Overall, Fasciola hepatica coinfection is associated with weaker inflammatory responses in the adventitial layer. Nonetheless, it is also associated with decreased numbers of cysts and intensities of infection and an absence of fertile liver ECs. 
We could not prove whether polyparasitism between Fasciola hepatica and Echinococcus granulosus was synergistic or antagonistic. Echinococcal cyst samples were obtained at abattoirs from naturally infected animals. It is not possible to determine which parasite enters the host first. Fasciola hepatica adult worms were not evaluated. We only sampled cattle with cystic echinococcosis only and coinfection but did not include cattle infected only with Fasciola hepatica. Further experimental studies are needed to better define the interaction involved in coinfections.

\section{Acknowledgements}

The authors would like to thank Mr. Steve Stoore for his valuable help in proofreading and correcting the paper. We would also like to thank the local health services for collaborating in the sample obtainment process in the abattoirs.

\section{Authors' contributions}

$\mathrm{RP}$ conceived this project, designed the experiments and reviewed the manuscript. $\mathrm{CH}$ and CS performed the experiments and analysed and interpreted the data. $\mathrm{CH}$ drafted the manuscript. $\mathrm{MH}$ analysed and interpreted the data. All authors read and approved the final manuscript.

\section{Funding}

This research was supported by ANID-FONDECYT Grant No. 1190817.

\section{Availability of data and materials}

All data generated or analysed during this study are included in this published article [and its supplementary information files].

\section{Ethics approval and consent to participate}

This study was approved by the Universidad Andres Bello ethics board.

\section{Competing interests}

The authors declare that they have no competing interests.

\section{Author details}

${ }^{1}$ Laboratorio de Medicina Veterinaria, Escuela de Medicina Veterinaria, Facultad de Ciencias de la Vida, Universidad Andres Bello, Santiago, Chile. ${ }^{2}$ Instituto de Ciencias Agroalimentarias, Animales y Ambientales (ICA3), Universidad de O'Higgins, San Fernando, Chile. ${ }^{3}$ Laboratorio de Biología Periodontal y Departamento de Patología y Medicina Oral, Facultad de Odontología, Universidad de Chile, Santiago, Chile.

Received: 10 February 2020 Accepted: 11 May 2020

Published online: 05 June 2020

\section{References}

1. Behnke JM (2008) Structure in parasite component communities in wild rodents: predictability, stability, associations and interactions.... or pure randomness? Parasitology 135:751-766

2. Blackwell AD, Martin M, Kaplan H, Gurven M (2013) Antagonism between two intestinal parasites in humans: the importance of co-infection for infection risk and recovery dynamics. Proc Biol Sci 280:20131671

3. Booth M, Bundy DA (1992) Comparative prevalences of Ascaris lumbricoides, Trichuris trichiura and hookworm infections and the prospects for combined control. Parasitology 105:151-157

4. Nacher M (2002) Worms and malaria: noisy nuisances and silent benefits. Parasite Immunol 24:391-393

5. Druilhe P, Tall A, Sokhna C (2005) Worms can worsen malaria: towards a new means to roll back malaria? Trends Parasitol 21:359-362

6. Pedersen AB, Fenton A (2007) Emphasizing the ecology in parasite community ecology. Trends Ecol Evol 22:133-139
7. Moreau E, Chauvin A (2010) Immunity against helminths: interactions with the host and the intercurrent infections. J Biomed Biotechnol 2010:428593

8. Everts B, Smits HH, Hokke CH, Yazdanbakhsh M (2010) Helminths and dendritic cells: sensing and regulating via pattern recognition receptors, Th2 and Treg responses. Eur J Immunol 40:1525-1537

9. Mendez-Samperio P (2012) Immunological mechanisms by which concomitant helminth infections predispose to the development of human tuberculosis. Korean J Parasitol 50:281-286

10. Viney ME, Graham AL (2013) Patterns and processes in parasite coinfection. Adv Parasitol 82:321-369

11. Gruner DS, Kolekar A, MCLaughlin JP, Strong DR (2009) Host resistance reverses the outcome of competition between microparasites. Ecology 90:1721-1728

12. Silva-Alvarez V, Folle AM, Ramos AL, Zamarreno F, Costabel MD, Garcia-Zepeda E, Salinas G, Corsico B, Ferreira AM (2015) Echinococcus granulosus antigen B: a hydrophobic ligand binding protein at the host-parasite interface. Prostaglandins Leukot Essent Fatty Acids 93:17-23

13. Agudelo Higuita NI, Brunetti E, McCloskey C (2016) Cystic echinococcosis. J Clin Microbiol 54:518-523

14. Thompson RC (2017) Biology and systematics of Echinococcus. Adv Parasitol 95:65-109

15. Wuhrer M, Grimm C, Dennis RD, Idris MA, Geyer R (2004) The parasitic trematode Fasciola hepatica exhibits mammalian-type glycolipids as well as Gal(beta1-6)Gal-terminating glycolipids that account for cestode serological cross-reactivity. Glycobiology 14:115-126

16. Paredes R, Jimenez V, Cabrera G, Iraguen D, Galanti N (2007) Apoptosis as a possible mechanism of infertility in Echinococcus granulosus hydatid cysts. J Cell Biochem 100:1200-1209

17. Stoore $C$, Andrade $C$, Hidalgo C, Correa F, Jimenez M, Hernandez M, Paredes R (2018) Echinococcus granulosus hydatid cyst location is modified by Fasciola hepatica infection in cattle. Parasit Vectors 11:542

18. Rigano R, Profumo E, loppolo S, Notargiacomo S, Ortona E, Teggi A, Siracusano A (1995) Immunological markers indicating the effectiveness of pharmacological treatment in human hydatid disease. Clin Exp Immunol 102:281-285

19. Vuitton DA (2003) The ambiguous role of immunity in echinococcosis: protection of the host or of the parasite? Acta Trop 85:119-132

20. Amri M, Aissa SA, Belguendouz H, Mezioug D, Touil-Boukoffa C (2007) In vitro antihydatic action of IFN-gamma is dependent on the nitric oxide pathway. J Interferon Cytokine Res 27:781-787

21. Shepherd JC, Aitken A, McManus DP (1991) A protein secreted in vivo by Echinococcus granulosus inhibits elastase activity and neutrophil chemotaxis. Mol Biochem Parasitol 44:81-90

22. Rigano R, Buttari B, Profumo E, Ortona E, Delunardo F, Margutti P, Mattei V, Teggi A, Sorice M, Siracusano A (2007) Echinococcus granulosus antigen B impairs human dendritic cell differentiation and polarizes immature dendritic cell maturation towards a Th2 cell response. Infect Immun 75:1667-1678

23. Zheng $Y$ (2013) Strategies of Echinococcus species responses to immune attacks: implications for therapeutic tool development. Int Immunopharmacol 17:495-501

24. Diaz A, Willis AC, Sim RB (2000) Expression of the proteinase specialized in bone resorption, cathepsin $\mathrm{K}$, in granulomatous inflammation. Mol Med 6:648-659

25. Vatankhah A, Halasz J, Piurko V, Barbai T, Raso E, Timar J (2015) Characterization of the inflammatory cell infiltrate and expression of costimulatory molecules in chronic Echinococcus granulosus infection of the human liver. BMC Infect Dis 15:530

26. Dorosti Z, Tolouei S, Khanahmad H, Jafari R, Jafaee F, Sharafi SM, Darani HY (2016) IL-4 gene expression in adventitial layer (fibrous layer) of hepatic ovine and bovine hydatid cysts. J Parasit Dis 40:855-859

27. Barnes TS, Hinds LA, Jenkins DJ, Bielefeldt-Ohmann H, Lightowlers MW, Coleman GT (2011) Comparative pathology of pulmonary hydatid cysts in macropods and sheep. J Comp Pathol 144:113-122

28. Vismarra A, Mangia C, Passeri B, Brundu D, Masala G, Ledda S, Mariconti M, Brindani F, Kramer L, Bacci C (2015) Immuno-histochemical study of ovine cystic echinococcosis (Echinococcus granulosus) shows predominant T cell infiltration in established cysts. Vet Parasitol 209:285-288 
29. Sakamoto T, Cabrera PA (2003) Immunohistochemical observations on cellular response in unilocular hydatid lesions and lymph nodes of cattle. Acta Trop 85:271-279

30. Lewall DB (1998) Hydatid disease: biology, pathology, imaging and classification. Clin Radiol 53:863-874

31. Kul O, Yildiz K (2010) Multivesicular cysts in cattle: characterisation of unusual hydatid cyst morphology caused by Echinococcus granulosus. Vet Parasitol 170:162-166

32. Rogan MT, Bodell AJ, Craig PS (2015) Post-encystment/established immunity in cystic echinococcosis: is it really that simple? Parasite Immunol $37: 1-9$

33. Abdel-Rahman EH, Abdel-Megeed KN, Abuel-Ezz NM (2003) Cross-reaction: a common trait among helminthes. J Egypt Soc Parasitol 33:457-47

34. O'Neill SM, Mills KH, Dalton JP (2001) Fasciola hepatica cathepsin L cysteine proteinase suppresses Bordetella pertussis-specific interferongamma production in vivo. Parasite Immunol 23:541-547

35. Flynn RJ, Mannion C, Golden O, Hacariz O, Mulcahy G (2007) Experimental Fasciola hepatica infection alters responses to tests used for diagnosis of bovine tuberculosis. Infect Immun 75:1373-1381

36. SAG (2018) Informe beneficio y hallazgos patológicos en mataderos nacionales 2017

37. Hidalgo C, Garcia MP, Stoore C, Ramirez JP, Monteiro KM, Hellman U, Zaha A, Ferreira HB, Galanti N, Landerer E, Paredes R (2016) Proteomics analysis of Echinococcus granulosus protoscolex stage. Vet Parasitol 218:43-45

38. Yanagida T, Mohammadzadeh T, Kamhawi S, Nakao M, Sadjjadi SM, Hijjawi N, Abdel-Hafez SK, Sako Y, Okamoto M, Ito A (2012) Genetic polymorphisms of Echinococcus granulosus sensu stricto in the Middle East. Parasitol Int 61:599-603

39. Correa F, Stoore C, Horlacher P, Jimenez M, Hidalgo C, Alvarez Rojas CA, Figueiredo Barros G, Bunselmeyer Ferreira H, Hernandez M, Cabrera G, Paredes R (2018) First description of Echinococcus ortleppi and cystic echinococcosis infection status in Chile. PLoS One 13:e0197620
40. Hidalgo C, Stoore C, Strull K, Franco C, Correa F, Jimenez M, Hernandez M, Lorenzatto K, Ferreira HB, Galanti N, Paredes R (2019) New insights of the local immune response against both fertile and infertile hydatid cysts. PLoS One 14:e0211542

41. Sohair IB, Eman MN (2009) Histopathological and bacteriological studies on livers affected with fascioliasis in cattle. Egypt J Comp Pathol Clinic Pathol 22:19-45

42. Wachira TM, Macpherson CN, Gathuma JM (1991) Release and survival of Echinococcus eggs in different environments in Turkana, and their possible impact on the incidence of hydatidosis in man and livestock. J Helminthol 65:55-61

43. Lahmar S, Trifi M, Ben Naceur S, Bouchhima T, Lahouar N, Lamouchi I, Maamouri N, Selmi R, Dhibi M, Torgerson PR (2013) Cystic echinococcosis in slaughtered domestic ruminants from Tunisia. J Helminthol 87:318-325

44. Ibrahim MM (2010) Study of cystic echinococcosis in slaughtered animals in Al Baha region, Saudi Arabia: interaction between some biotic and abiotic factors. Acta Trop 113:26-33

45. Guo ZH, Kubo M, Kudo M, Nibe K, Horii Y, Nonaka N (2011) Growth and genotypes of Echinococcus granulosus found in cattle imported from Australia and fattened in Japan. Parasitol Int 60:498-502

46. Fu Y, Browne JA, Killick K, Mulcahy G (2017) Network analysis of the systemic response to Fasciola hepatica infection in sheep reveals changes in fibrosis, apoptosis, toll-like receptors $3 / 4$, and B cell function. Front Immunol 8:485

\section{Publisher's Note}

Springer Nature remains neutral with regard to jurisdictional claims in published maps and institutional affiliations.
Ready to submit your research? Choose BMC and benefit from:

- fast, convenient online submission

- thorough peer review by experienced researchers in your field

- rapid publication on acceptance

- support for research data, including large and complex data types

- gold Open Access which fosters wider collaboration and increased citations

- maximum visibility for your research: over $100 \mathrm{M}$ website views per year

At $\mathrm{BMC}$, research is always in progress.

Learn more biomedcentral.com/submissions 